\title{
JULIÁN MEZA Y LA \\ AMISTAD
}

José María Espinasa

\section{No recuerdo exactamente cuándo} empecé a oír hablar de Julián Meza, pero un día estaba en la mesa, hablando y bromeando como si hubiera estado ahí desde siempre, formaba ya parte de la conversación colectiva. Yo había leído un largo artículo suyo, si no recuerdo mal en Uno más Uno, sobre los nuevos filósofos franceses, del que tengo presente una argumentación que después sería casi una insignia, en contra de los "maestros del pensar", en donde ese magisterio no es enseñanza, sino amaestramiento. Y aunque leí con cierta fruición a muchos de aquellos nuevos filósofos que él nos presentó, en especial a Andre Gluskmann, siempre lo consideré a él más interesante que a sus presentados.

El beber y el comer como actividad intelectual se regaba con las conversaciones sobre pensadores que conocía poco o simplemente no sabía quiénes eran, por ejemplo Edgar Morin, una de sus admiraciones sostenidas hasta el día de hoy (lo cual no es poco decir, ya que Julián dice que las amistades son para siempre, pero las admiraciones más bien efímeras), Cornelius Castoriadis, Cioran, Debord, etc.

Los que lo conocían rápido y mal se quejaban de su sesgo afrancesado. Años después en París, al oírlo imitar acentos en la urbe, me di cuenta de que el adjetivo estaba mal usado, Julián no era un afrancesado, los afrancesados eran los franceses, que le copiaban a él su manejo

* Editor y escritor. 
JOSÉ MARÍA ESPINASA

extraordinario de una lengua con demasiada capacidad de matiz como para abandonarla en manos de ellos, que no la saben usar, y tienen que venir griegos, rumanos, búlgaros y hasta un mexicano para enseñarles a usarla bien. En esas pláticas de sobremesa también lo vi ejercer eso que ahora los economistas llaman doble reporte y que el entusiasmo y la admiración descubrió mucho antes: poder admirar hasta la divinización a un autor a la vez que, y por eso mismo, ser de una exigencia absoluta con sus argumentos.

Lo era, por ejemplo, con Octavio Paz, a quien admiraba mucho, pero de quien era muy crítico, sin pensar que hubiera contradicción o paradoja en ello. Por su lado, Paz lo estimaba y lo respetaba, le gustaba su tono iconoclasta y provocador, aunque supiera que eso lo volvía incómodo y difícil de incluir entre los gregarios cercanos a la revista Vuelta. Es curioso que Julián tuviera la virtud de provocar reacciones radicales: o lo querían cocinar en salsa verde o lo querían mucho. De más está decir que me cuento entre los últimos. Como a los autores de su edad les resultaba muy incómodo y Julián los consideraba en su mayoría débiles mentales, se instaló en la mesa de los nacidos veinte años después.

Hace años, cuando el primer número de Estudios salió de las prensas, Julián, su director entonces y -milagros de las continuidades en un país 142 poco adicto a ellas-director ahora, insistía en convencernos de que las revistas académicas eran, si no un espacio ideal, un lugar posible para realizar algo que vagamente llamaremos aquí "la crítica de la cultura". Había argumentos de peso: las revistas culturales comunes y corrientes se peleaban por ocupar un espacio de poder, como ocurría con Vuelta y Nexos, y ese término -"poder"- significaba exactamente lo contrario de crítica: los temas, autores y juicios se acomodaban a las exigencias de un grupo político que representaba un potencial anunciante, puestos y prerrogativas en la burocracia y cosas similares. Las revistas académicas parecían ser ajenas a eso, pero tenían en su contra la glosolalia acumulada de las jergas universitarias y los cotos cerrados de los especialistas. Hacer una revista académica viva era un desafío y lo sigue siendo ahora.

La verdad es que el entusiasmo de Julián Meza entre sus amigos escritores fue prendiendo poco a poco, no como una hoguera, pero sí 
como una brasa que conservaba en su interior rescoldos. No estaba lejos el lamentable final de la revista Diálogos, que dirigía Ramón Xirau para El Colegio de México, uno de los modelos de revistas universitarias no ceñidas a la condición académica como un lastre, como lo había sido antes de ella, La Revista de la Universidad de México, bajo la dirección de Jaime García Terrez. Desde luego, el chiste está en hacer flexible el concepto de academia o de universidad y -ahora de forma más imperiosa que entonces- en desligar el sentido de publicar-hacer público- un texto, de la necesidad de acumular puntos y ganar estímulos en el Conacyt y estructuras similares. La tan admirable cultura del pie de página se desvirtúa en esa carrera salarial que convierte al pie en pezuña.

Se podría decir, sin miedo a equivocarse, que una de las principales tareas de una revista ligada a una casa de estudios es liberarse de los condicionamientos del organismo mencionado, que preocuparse menos por estar "indexados", por pertenecer al padrón de excelencia, y más por sus lectores es una apuesta necesaria para su calidad. Esto permite a los escritores que colaboran en ella no estar pensando todo el tiempo en los puntos, sino en sus verdaderos intereses intelectuales, los que rara vez suelen coincidir. Debe responder también a la personalidad de los que la hacen, tener algo de capricho. Por ejemplo, es evidente que autores como Castoriadis, Morin o Foucault, queridos por Julián Meza en algún momento de su trayectoria intelectual, se hicieron, gracias a las páginas de la revista, caprichos de otros escritores.

El entusiasmo de Julián Meza, mencionado líneas arriba, no cundió como una hoguera porque la mayoría de nosotros batallábamos entonces en las redacciones de los periódicos, suplementos y revistas de quiosco, en espacios que nos parecían -en nuestra ingenuidad-más afines.

Alguna vez, en una conversación sobre las revistas académicas, pregunté, con cierta impertinencia, que si alguien había visto alguna persona comprando un ejemplar de la Nueva Revista de Filología en Sanborn's... para llevarla al siquiátrico. Antonio Alatorre, cortésmente, me contestó que dicha revista agotaba su tiraje sin necesidad de compradores en Sanborn's. Es cierto, pero no creo que les suceda a muchas de estas revistas. Indica, sin embargo, el sentido de editarlas: la conversación entre los propios académicos. Detengamos un poco en 
JOSÉ MARÍA ESPINASA

esto. De lo dicho anteriormente se desprende que académico y especialista son sinónimos y esto no es verdad. Este malentendido ha provocado un distanciamiento que es casi una fractura irreparable entre el lego y el académico.

Uno de los objetivos de la literatura académica, sobre todo si atañe a las ciencias humanas, debe ser precisamente su inteligibilidad, $\mathrm{su}-\mathrm{y}$ perdonen la palabreja- su "entendibilidad". Debe entenderlo el que está en el ajo, pero también el que no. Escribir complicado no es ser más profundo, sino ser más confuso. Así, una revista académica no debería limitar su destinatario al grupo de cofrades que, además y para colmo de males, pocas veces está interesado en leerse entre sí. Resultado: el diálogo, ya olvídense de la polémica, no se da nunca, se teje una red de monólogos que ni siquiera se miran de frente.

Allí entra en juego la mano de un director. Julián Meza es bastante terminante e impositivo en sus escritos personales, pero por lo mismo, le gusta la polémica, busca rivales, suelta retos, y esto se nota en su conducción de la revista. Por ejemplo, está claro que no se cierra a que las páginas de Estudios sean una ventana abierta a propuestas que vienen de otras lenguas, en sus números - con altibajos-abundan traducciones. Esto me parece un síntoma de salud; tampoco se niega

144 a textos de considerable longitud, lo cual es también elogiable en una cultura cada vez más regida por la comunicación telegráfica, deudora en los tics de la brevedad, más de la publicidad que de la aún noble clave Morse. Es decir: Julián entiende que sus lectores son sus amigos y los trata como tales.

En los mejores momentos de Estudios uno nota la actividad tras bambalinas, al director, al jefe de redacción, a los miembros del consejo solicitando textos y proponiendo temas y autores. Esto no siempre llega a la página impresa, pero le da color a las que sí alcanzan esa condición, les da tibieza, pulso. Crean el contexto en el que ella-Estudios-, pero también otras, deben ser leídas. Por ejemplo, es lógico el interés que el mercado y los lectores tienen por Foreign Affairs, pero ¿se entendería ésta sin el peso intelectual de Estudios? Yo creo que no, y entre otras cosas, porque muchas veces los pisos son también techos de otras viviendas: no es éste el lugar para mostrarlo, pero estoy seguro de que muchas 
de las más importantes revistas surgidas en los noventa y en lo que va del nuevo milenio, abrevaron en las virtudes de Estudios.

Una de las cosas a las que siempre se alude en las discusiones sobre las revistas académicas es lo que llamamos actualidad. Hay algunas, pongo el caso de la espléndida Metapolítica, que ha alcanzado una actualidad notable. Para que lo actual sea un elogio, hay que precisar primero su condición: esa vinculación con el calendario tiene también sus asegunes y no siempre beneficia a una publicación académica. Hay otras que consiguen ser actuales al ignorar la actualidad, y creo que es el caso de Estudios (también podría ser el caso de la espléndida Istor, dirigida por Jean Meyer). Es decir: quieren ser actuales no en lo que está hoy, sino en lo que estará mañana. Por favor, nada más lejos de pensar en profetas, pues ya sabemos que el futuro es siempre nostalgia. Así que más bien hay que ocuparse del pasado, que es lo que está por venir.

Por ejemplo, revisando a vuela pluma algunos números atrasados de Estudios encuentro, en el número nueve, un homenaje a Saint John Perse, con correspondencia y poemas traducidos por José Luis Rivas. El número es de 1987. Unos tres años después, el interés que Rivas manifestó sobre el autor de Anábasis, se concretó en un primer volumen de obras completas del francés, publicado por la UAM. El proyecto incluía dos volúmenes más que nunca salieron. Hoy, quince años después, sé que el poeta veracruzano sigue trabajando en los textos del caribeño. En general, las revistas son así los semilleros de futuros frutos editoriales, vasos comunicantes entre diversas ideas y estilos. Y, retrospectivamente, se les puede aplicar una especie de prueba del añejo: una buena revista resiste la lectura de sus números atrasados, es más, muchas veces crece con el tiempo, se revelan aspectos que en su momento - es decir, en su actualidad- no se veían. Esto ocurre con Estudios, y tal vez por eso valdría la pena elaborar un índice que diera cuenta del camino recorrido hasta ahora y sirviera de radiografía de los años transcurridos.

Para terminar estas apresuradas reflexiones sobre las revistas académicas y sobre los cien números de Estudios, quisiera señalar que existe el lector normal, común, que suele guardar distancia con este tipo de publicaciones; existe otro lector, el que pertenece al gremio, que -al menos teóricamente- debería tener mucha cercanía con ellas, pero 
no ocurre así, entre otras cosas porque no suelen interesarse en lo que hacen sus colegas, y ese interés crea el sentido de comunidad. No deja de ser curioso que en México abunden las revistas y no sólo académicas, pero que no tengamos comunidad de lectores, que nuestros promedios de lecturas sean de los más bajos de la lengua española, y a pesar de ello sigamos pregonando nuestra condición de país culto.

Mantener a lo largo de los años una revista en medio de ese panorama nada halagador es un gesto de resistencia a la uniformidad y un guante que se tira al ruedo de lo que queda de esa comunidad para provocar un síntoma de reconstitución. La verdad es que, al revisar los números de Estudios, me ha sorprendido darme cuenta de que Julián tenía razón, de que había que hacer una revista así, que la ha mantenido con un alto nivel de calidad y que no puedo pensar en el Instituto Tecnológico Autónomo de México sin Estudios. Pero sobre todo, a Julián que la ha hecho como un espacio de amistad. A esta palabra, el español le tiene miedo, incluso hay un libro de Bataille que se llama en francés La amistad ( $L$ 'amitié), pero que el traductor al castellano le puso un título muy alambicado, ya no recuerdo cuál. Según sé de buena fuente, es decir, por sus alumnos, Julián también hizo de sus clases una forma de practicar la amistad, de interesar a los oyentes en las personas y en sus comportamientos, aproximarse a los textos en un diálogo. Rendirle un homenaje a él y a los cien números de su revista es también una manera de refrendarle mi amistad. 